\title{
Effect of Complete Denture on Memory and Depression Status in Elderly Patients
}

\author{
${ }^{1}$ Bahruddin Thalib, ${ }^{2}$ Ike D Habar, ${ }^{3}$ Vinsensia Launardo, ${ }^{4}$ Asmawati Amin, ${ }^{5}$ Rafikah Hasyim
}

\section{ABSTRACT}

Aim: One common complaint among the elderly is memory decline and tooth loss due to aging. Tooth loss affects masticatory function and reportedly may also contribute to the occurrence of memory disorders and depression. The aim of this study was to analyze the influence of complete denture use on memory capacity and depression level in elderly patients.

Materials and methods: The study was conducted at Hasanuddin University Dental Hospital. The study was a clinical experiment with nonrandomized design with pre- and posttests. A purposive sampling technique was used with six fully edentulous patients willing to participate. Memory status was measured using the Mini-Mental State Examination (MMSE), and level of depression was evaluated using the geriatric depression scale (GDS). Memory status and level of depression measurements were performed before using complete dentures and 1 month after using complete dentures. The data were analyzed using statistical paired t-test.

Results: At the $95 \%$ confidence level $p<0.05$, the results showed a significant difference (increase) between initial MMSE average value (25.67) and the final MMSE average value (26.83). There was no significant change in the level of depression $p>0.05$ between initial GDS (5.17) and final GDS (4.17).

Conclusion: This study indicates that the use of complete dentures by fully edentulous patients may improve memory status, but does not seem to have a significant impact on depression level.

Clinical significance: The relationship between tooth loss, depression, and memory is a complex relationship, where depression could be both a cause and an effect of memory dysfunction. Improvement of memory status using complete dentures will help to restore confidence level of elderly patients.

Keywords: Complete denture, Depression, Elderly, Memory status.

How to cite this article: Thalib B, Habar ID, Launardo V, Amin A, Hasyim R. Effect of Complete Denture on Memory and Depression Status in Elderly Patients. World J Dent 2017;8(6):457-460.

Source of support: Nil

Conflict of interest: None

1,2Department of Prosthodontics, Faculty of Dentistry, Hasanuddin University, Makassar, Indonesia

3-5 Department of Oral Biology, Faculty of Dentistry, Hasanuddin University, Makassar, Indonesia

Corresponding Author: Rafikah Hasyim, Department of Oral Biology, Faculty of Dentistry, Hasanuddin University, Makassar Indonesia, Phone: +6282112532676, e-mail: rafikahhasyim@ gmail.com

\section{INTRODUCTION}

After tooth eruption is complete, teeth occlude and perform the function of mastication or chewing, and the brain will begin to store new memories. Sensory receptors in the periodontal ligament adapt to a variety of functions, including mastication. After occlusion-mastication function is stabilized, sensory receptors that include dental periodontal mechanoreceptors, proprioceptive receptors, nociceptive receptors, and other related receptors will build a functional neuronal connection with the sensory cortex, consciously or unconsciously. Having been performed over the years, the stable occlusion-mastication functional memory has become a basic function and an enjoyable physical action. ${ }^{1,2}$

The stable action of occlusion-mastication is not only a mechanical function. Before starting to eat an apple, for example, a memory that connects the occlusionmastication action will remind us of the taste experienced when we bite the apple, and we would expect a crisp, juicy, fragrant, and sweet sensory input. Memories picked up shortly before this action are memories derived from visual sensory receptors, olfactory, gustatory, and periodontal mechanoreceptors. Once the apple is bitten, all sensory receptors will begin to identify, evaluate, and enjoy the fruit. It is a harmony of recognition, memory, and reflexes, consciously or unconsciously. Teeth play an important role in this process, enabling precise sensory receptors and comprehensive thorough coordination of this occlusion-mastication action. ${ }^{1-3}$

The occlusion-mastication action can be compared with "symphony orchestra" where each tooth is a musician playing their respective instruments and they are not interchangeable. If one or more musicians (teeth) change their function or missing, then the harmony of the orchestra will be affected by temporary or long-term vacancy, causing mental and physical stress. The brain will remap the cortical sensory and motor pathways to adapt to the stress and maintain the effectiveness of occlusion-mastication. ${ }^{4-7}$

Memory and intellectual loss could make a previously independent and self-confident person lose their confidence. Furthermore, the elderly are particularly vulnerable to depression. For severe memory and intellectual loss, this process can happen in a short time and have a fatal outcome. Therefore, it is important to prevent 
Table 1: The MMSE and GDS scores before and after full denture treatment

\begin{tabular}{|c|c|c|c|c|c|c|c|c|c|c|}
\hline \multirow[b]{2}{*}{ Subject } & \multicolumn{2}{|c|}{ Gender } & \multirow{2}{*}{$\begin{array}{l}\text { Age } \\
\text { (years) }\end{array}$} & \multirow[b]{2}{*}{ Education } & \multirow[b]{2}{*}{ Occupation } & \multirow{2}{*}{$\begin{array}{l}\text { Edentulous } \\
\text { (years) }\end{array}$} & \multicolumn{2}{|c|}{ MMSE } & \multicolumn{2}{|c|}{ GDS } \\
\hline & $M$ & $F$ & & & & & Pre & Post & Pre & Post \\
\hline 1 & & 1 & 52 & Junior high & Housewife & 5 & 29 & 30 & 7 & 4 \\
\hline 2 & & 1 & 55 & Elementary school & Housewife & 3 & 27 & 28 & 4 & 4 \\
\hline 3 & & 1 & 58 & Elementary school & Housewife & 4 & 27 & 27 & 9 & 7 \\
\hline & & 1 & 50 & Elementary school & Housewife & 3 & 23 & 25 & 4 & 4 \\
\hline 5 & 1 & & 64 & Senior high & Self-employed & 1 & 25 & 27 & 6 & 4 \\
\hline 6 & & 1 & 60 & Elementary school & Retired & 3 & 23 & 24 & 1 & 2 \\
\hline
\end{tabular}

deterioration of memory and intellect in the elderly as early as possible. ${ }^{4,8}$ As mastication is associated with memory, this study aimed to analyze the effect of complete denture use on the status of memory and depression in elderly patients, who had lost their natural teeth.

\section{MATERIALS AND METHODS}

This study was a clinical and experimental study using pre- and post-test designs. A purposive sampling method was used. The sample population was obtained from the Department of Prosthodontics, Hasanuddin University Dental Hospital. The procedures were in accordance with the ethical standards of the responsible committee on human experimentation and approved by the Ethical Committee, Faculty of Medicine, Hasanuddin University. The sample population comprised patients who lost all their teeth for 3 months, aged 50 to 65 years, had not suffered from hypertension, diabetes mellitus, never suffered from stroke, whose alveolar ridges had not undergone large resorption, and they had not had a flat or flabby ridge. There were six patients willing to participate in this study, who signed the written informed consent form. Cognitive status was measured using MMSE with 24 to 30 for normal appraisal; 17 to 23 for probable cognitive impairment; ${ }^{8}$ and 0 to 16 for definite cognitive impairment. Depression status was measured using the GDS with a value $\geq 5$ indicating depression. ${ }^{9}$ Initial data (pretest) were collected from the entire sample for MMSE and GDS before complete denture rehabilitation treatment. The complete denture treatment was based on standard operating procedures applied in the Department of Prosthodontics, Hasanuddin University Dental Hospital. After the insertion of complete dentures, all samples were given instructions for use, maintenance, and control for 1 week after insertion of the full denture. The MMSE and GDS were remeasured (posttest) 4 weeks after denture insertion.

\section{RESULTS}

There were five female and one male patients aged 52 to 64 years in the sample. The majority had had educational attainment level of primary school and worked as

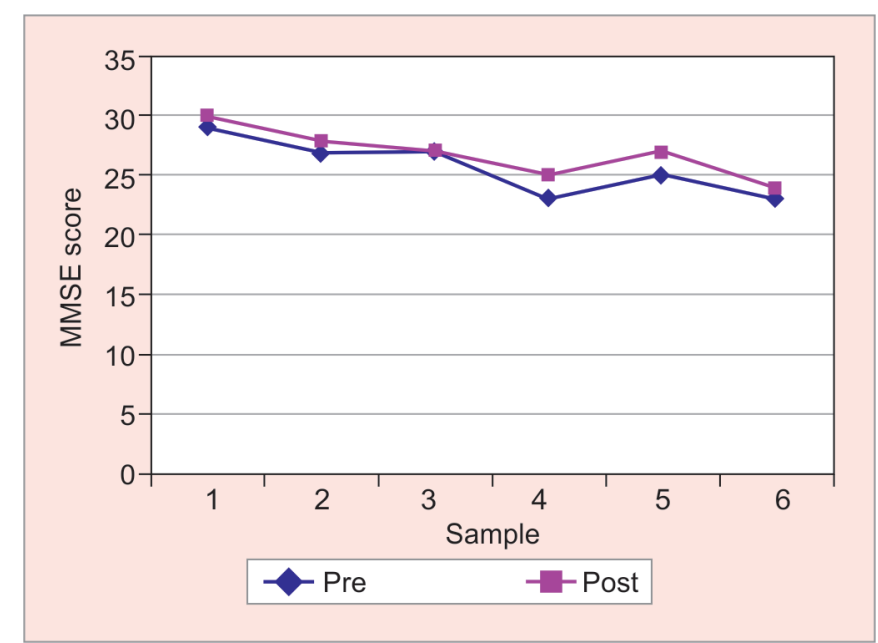

Graph 1: Pre- and post-MMSE score

housewives (Table 1). Data were analyzed and processed using statistical program IBM Statistical Package for the Social Sciences version 22, and a paired t-test was applied.

\section{Mini-Mental State Examination}

The results showed that the initial mean of MMSE score was 25.67 and the final mean of MMSE score was 26.83 . Based on the result of paired t-test, this increase (0.953) in the value of MMSE score before and after using complete dentures was highly significant $(p<0.01)$, as shown in Graph 1.

\section{Geriatric Depression Scale}

The mean score of GDS baseline was 5.17, while the mean score of final GDS was 4.17. However, the results of the paired t-test gave a significant value of 0.18 , thus showing no significant effect $(p>0.05)$ at the $95 \%$ confidence level (Graph 2).

\section{DISCUSSION}

Tooth loss is a problem that is commonly found in elderly people, who are generally associated with poor oral health. Based on the results of the Basic Medical Research in 2013, the proportion of people aged 65 years with normal dental function was only $41.2 \%$, still below the World Health Organization target (75\%). When teeth 


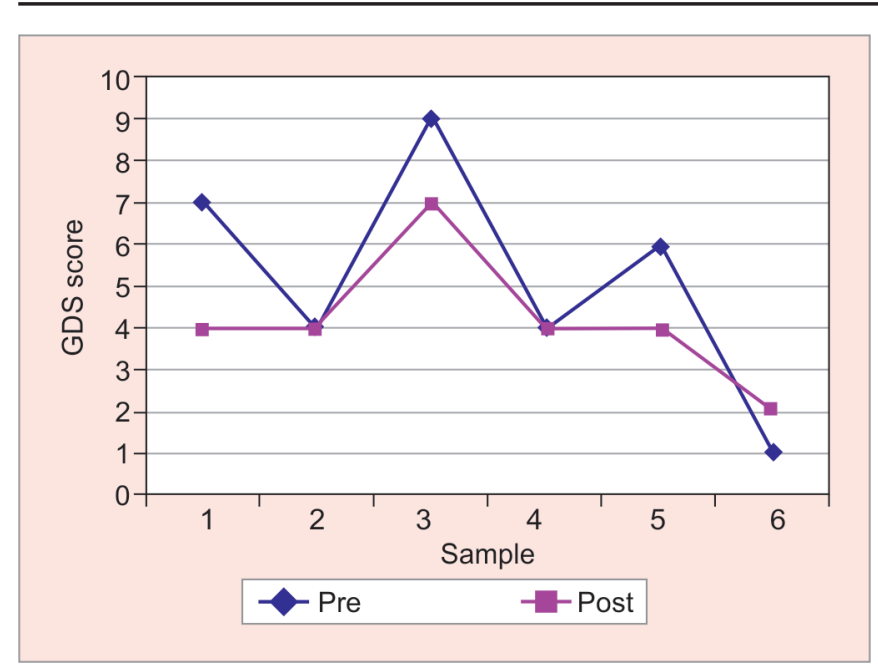

Graph 2: Pre- and post-GDS score

are missing, periodontal sensory and pulp receptors including mechanoreceptor, propioception receptors, nociceptive receptors, and other related receptors, and nerve endings are also missing. ${ }^{4}$ Mastication is a complex harmonization of conscious and unconscious interaction between memory, reflexes, and other functions as a nonstop transmission of neural. Teeth play an important role, where nerve endings and sensory receptors could be involved in a careful and thorough coordinated process in the occlusion-mastication action. If one or more teeth change its function or is missing, then the harmony will be affected, which causes temporary or long-term vacancy and lead to mental and physical stress. To adapt to the stress that occurs and maintain the effectiveness of occlusion-mastication toward the changes, the brain will perform a sensory cortical and motoric remapping. ${ }^{2}$ Some studies using experimental animals treated with occlusion hypofunction showed memory loss and performing poorly on memory and learning tests, but the memory function will increase when the occlusion is restored. ${ }^{10-12}$ This could explain that complete denture rehabilitation will increase occlusion-mastication capability, which will stimulate the activity in the cerebral cortex and prevent brain function degradation due to an increase of cerebral blood flow and activation of the cortex during jaw movement. Blood oxygen level was increased in the prefrontal cortex and hippocampus and it plays an important role in learning and memory. ${ }^{3,13}$ Hippocampus is the main region of central nervous system that is influenced by masticatory hypofunction that have an effect on decreased density of pyramid neuron and dendritic spine. ${ }^{3}$ Related to this study, some researchers also suggested that tooth loss can interfere with masticatory function, which will lead to cognitive impairment in the elderly. 2,14-17

The GDS scores did not show a significant correlation between pre- and postocclusion-mastication rehabilitation. However, in some people, we found clinical value deterioration. This was most likely associated with Eastern social and cultural factors that are very conventional. The author found that even though it has been approached in a familiar and friendly way as well as through asking questions indirectly based on instructions, some patients were still hesitant and possibly not tell the entire truth of their feelings. Another thing to note as well is the education level of patients, who were only educated up to primary school. This can lower their subjective expectations in life, so the level of depression was not significant. This is in contrast to the results reported by Davis et $\mathrm{al}^{12}$ that $45 \%$ of respondents reported of having a difficult time in dealing with their tooth loss. Okamoto et $\mathrm{ll}^{14}$ also reported a higher percentage of depression in samples with higher level of tooth loss. Davis et al ${ }^{12}$ also reported that $40 \%$ of participants having difficulty in accepting the loss of their teeth felt less confident and limited their outdoor activities. The relationship between tooth loss, depression, and memory is a complex relationship, where depression could be both a cause and an effect of memory dysfunction.

\section{CONCLUSION}

There was a significant correlation between the increase of memory strength after using complete dentures in elderly patients. On the contrary, the effect of complete dentures toward depression level was not significant although there was some improvements in the clinical depression score. Further study is needed to determine the capability and efficiency of mastication when using complete dentures in particular muscle activity and the aging process.

\section{CLINICAL SIGNIFICANCE}

The relationship between tooth loss, depression, and memory is a complex one where depression could be both a cause and an effect of memory dysfunction. Improvement of memory status using complete dentures will help to restore confidence level in the elderly patients.

\section{ACKNOWLEDGMENT}

The authors would like to thank the staff of Oral and Dental Hospital University of Hasanuddin for their help in this study.

\section{REFERENCES}

1. Byrne, JH. Learning and memory in neuroscience. Chapter 7. Houston (TX): The University of Texas; 1997. pp. 1-13.

2. Jou YT. Tooth loss and brain damage: multiple recurrent cortical remapping hypothesis. J Prosthodont Implantol 2012;1(1):6-11.

3. Teixeira FB, Fernandes LM, Noronha PA, dos Santos MA, Gomes-Leal W, Ferraz Maia CS, Lima RR. Masticatory deficiency as a risk factor for cognitive dysfunction. Int J Med Sci 2014 Jan;11(2):209-214. 
4. Junge, C. Improving memory, understanding age-related memory loss. Boston (MA): Book Baby; 2014. pp. 2-5.

5. Foltyn, P. Dementia and your teeth. London: Alzheimer's Disease International; 2013. pp. 1-4.

6. MacGill, M. What I Alzheimer's disease? Causes, symptoms and treatment. Brighton: MediLexicon International Limited, MNT; 2014. pp. 1-11.

7. Pedersen, PH.; Loe, H. Textbook of geriatric dentistry. Copenhagen: Munksgaard; 1990. pp. 1-2.

8. National Chronic Care Consortium. Tools for early identification, assessment, and treatment for people with Alzheimer's disease and dementia. Bloomington (IL): National Chronic Care Consortium and the Alzheimer's Association; 1998.

9. Njoto EN. Recognize depression in elderly using the geriatric depression scale (GDS) to support the diagnosis (in Indonesia). CDK 217 2014;41.

10. Watanabe K, Ozono S, Nishiyama K, Saito S, Tonosaki K, Fujita M, Onozuka M. The molarless condition in aged SAMP8 mice attenuates hippocampal fos induction linked to water maze performance. Behav Brain Res 2002 Jan;128(1):19-25.

11. Davey R, Jamieson $\mathrm{S}$. The validity of using the mini mental state examination in NICE dementia guidelines. J Neurol Neurosurg Psychiatry 2004 Feb;75(2):343-344.
12. Davis DM, Fiske J, Scott B, Radford DR. The emotional effects of tooth loss: a preliminary quantitative study. Br Dent J 2000 May;188(9):503-506.

13. Elsig F, Schimmel M, Duvernay E, Giannelli SV, Graf CE, Carlier S, Hermann FR, Michel JP, Gold G, Zekry D, et al. Tooth loss, chewing efficiency and cognitive impairment in geriatric patients. Gerodontology 2015 Jun;32(2):149-156.

14. Okamoto N, Morikawa M, Okamoto K, Habu N, Iwamoto J, Tomioka K, Saeki K, Yanagi M, Amano N, Kurumatani N. Relationship of tooth loss to mild memory impairment and cognitive impairment: findings from the Fujiwara-Kyo study. Behav Brain Funct 2010 Dec;6:77.

15. Park H, Suk SH, Cheong JS, Lee HS, Chang H, Do SY, Kang JS. Tooth loss may predict poor cognitive function in community-dwelling adults without dementia or stroke: the Present project. J Korean Med Sci 2013 Oct;28(10):1518-1521.

16. Tsakos G, Watt RG, Rouxel PL, de Oliveira C, Demakakos P. Tooth loss associated with physical and cognitive decline in older adults. J Am Geriatr Soc 2015 Jan;63(1):91-99.

17. Lexomboon D, Trulsson M, Wårdh I, Parker MG. Chewing ability and tooth loss: association with cognitive impairment in an elderly population study. J Am Geriatr Soc 2012 Oct;60(10):1951-1956. 